\title{
Epigenetic and Proteomic Expression Changes Promoted by Eating Addictive-Like Behavior
}

\author{
Samantha Mancino',5, Aurelijus Burokas',5,6, Javier Gutiérrez-Cuesta',5, Miriam Gutiérrez-Martos', \\ Elena Martín-García', Mariangela Pucci ${ }^{2}$, Anastasia Falconi ${ }^{2}$, Claudio D'Addario ${ }^{2,3}$, Mauro Maccarrone ${ }^{4,7}$ and \\ Rafael Maldonado*,1,7
}

'Departament de Ciencies Experimentals i de la Salut, Universitat Pompeu Fabra, Barcelona, Spain; ${ }^{2}$ Faculty of Bioscience and Technology for Food, Agriculture and Environment, University of Teramo, Teramo, Italy; ${ }^{3}$ Department of Clinical Neuroscience, Center for Molecular Medicine, Karolinska Institutet, Stockholm, Sweden; ${ }^{4}$ Center of Integrated Research, Campus Bio-Medico University of Rome, and European Center for Brain Research/Santa Lucia Foundation, Rome, Italy

\begin{abstract}
An increasing perspective conceptualizes obesity and overeating as disorders related to addictive-like processes that could share common neurobiological mechanisms. In the present study, we aimed at validating an animal model of eating addictive-like behavior in mice, based on the DSM-5 substance use disorder criteria, using operant conditioning maintained by highly palatable chocolate-flavored pellets. For this purpose, we evaluated persistence of food-seeking during a period of non-availability of food, motivation for food, and perseverance of responding when the reward was associated with a punishment. This model has allowed identifying extreme subpopulations of mice related to addictive-like behavior. We investigated in these subpopulations the epigenetic and proteomic changes. A significant decrease in DNA methylation of CNRI gene promoter was revealed in the prefrontal cortex of addict-like mice, which was associated with an

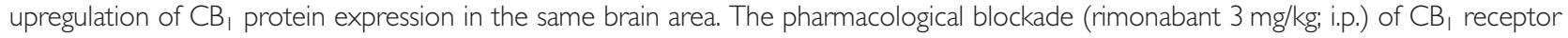
during the late training period reduced the percentage of mice that accomplished addiction criteria, which is in agreement with the reduced performance of $\mathrm{CB}_{1}$ knockout mice in this operant training. Proteomic studies have identified proteins differentially expressed in mice vulnerable or not to addictive-like behavior in the hippocampus, striatum, and prefrontal cortex. These changes included proteins involved in impulsivity-like behavior, synaptic plasticity, and cannabinoid signaling modulation, such as alpha-synuclein, phosphatase I-alpha, doublecortin-like kinase 2, and diacylglycerol kinase zeta, and were validated by immunoblotting. This model provides an excellent tool to investigate the neurobiological substrate underlying the vulnerability to develop eating addictive-like behavior. Neuropsychopharmacology (2015) 40, 2788-2800; doi:I 0.1038/npp.2015.129; published online 27 May 2015
\end{abstract}

\section{INTRODUCTION}

The increased incidence of obesity and overeating disorders represent a major health problem in developed countries. Based on the latest estimates, overweight affects $>30 \%$ and obesity $>15 \%$ of adults in the European Union (WHO, 2008), while in the USA $35.3 \%$ of adults are considered overweight and the obesity rate is $27.7 \%$ (Gallup, 2014). Obesity is defined as excessive fat accumulation that results from a caloric imbalance, meaning that the number of calories consumed exceeds the calories expended (Brownell, 2004). Unfortunately, few obese people achieve significant

* Correspondence: Professor R Maldonado, Laboratory of Neuropharmacology, Pompeu Fabra University, Dr. Aiguader, 88, Barcelona 08003, Spain, Tel: +3493 3160824, Fax: +3493 3160901,

E-mail: rafael.maldonado@upf.edu

${ }^{5}$ These authors contributed equally to this work.

${ }^{6}$ Present address: Laboratory of Neurogastroenterology, Alimentary Pharmabiotic Centre, University College Cork, Cork, Ireland.

${ }^{7}$ Equally senior authors.

Received 26 November 2014; revised 27 April 20I5; accepted 28 April 20I5; accepted article preview online 6 May 2015 weight reduction mainly owing to the difficult to control food intake. The low rate of success of treatments to prevent or reverse obesity highlights the fact that this condition is not only a metabolic disorder but also a behavioral alteration (Volkow and Wise, 2005). In agreement, obese individuals are led by an excessive motivational drive for food, eat more than intended, and make frequent unsuccessful efforts to control overeating. These behavioral alterations seem to be mediated by changes in the mesolimbic reward circuits that mimic the changes occurring during addictive-like behavior (Volkow et al, 2012). In addition, several behavioral modifications occurring during obesity that parallel to those described in DSM-5 for substance use disorder had allowed to hypothesize that overeating may be considered as an addictive-like behavior (Hebebrand et al, 2014). Binge eating disorder (BED) seems particularly linked to addiction given specific features of the disorder as compulsive eating, excess consumption despite adverse consequences, and diminished self-control over eating behavior. Indeed, the concept of eating addiction includes the loss of control over eating, the persistent desire for food, the unsuccessful efforts to control 
food use, the high motivation to seek the food, and the continued use despite negative consequences (Hebebrand et al, 2014). However, BED does not entirely overlap with drug addiction as the sense of feeling out-of-control occurs in BED when a large quantity of food is consumed during a discrete time period. In contrast, substance dependence is not marked by a specific time course of consumption but rather by drug use occurring over a longer time and in higher frequency. Moreover, addiction diagnosis places a greater emphasis on the contribution of the substance (addictive potential of drug) while $\mathrm{BED}$ diagnosis does not consider specific types of food consumed (merely the amount) (Gearhardt et al, 2011; Gearhardt et al, 2014). Furthermore, the possible development of an addictive-like behavior to food has been accepted (Gearhardt et al, 2013; Pretlow et al, 2015) and it is thought that it may participate in obesity, although normal-weight people may also be vulnerable to eating addiction. Eating addiction and BED do not entirely overlap; and despite multiple similarities, a diagnosis of food addiction was met by $57 \%$ of BED patients (Gearhardt et al, 2011). Eating addiction, BED, and the co-occurrence of both could have an implication in obesity due to the excess of food consumption. Although evidence of eating addiction has been found in normal-weight patients, a higher rate has been reported in obese patients (Gearhardt et al, 2011). Indeed, eating addiction has been considered as a behavior resembling drug addiction only in a subgroup of obese patients or binge eaters (Curtis and Davis, 2014), and genes involved in drug addiction may also be associated with eating addiction (Heber and Carpenter, 2011).

Epigenetics is the study of heritable changes that affect gene expression without changing the DNA sequence transducing environmental stimuli in stable alterations of DNA or chromatin structure (Jaenisch and Bird, 2003). Animal studies have shown that epigenetic mechanisms produced by repeated exposure to drugs mediate addictivelike behavior (Schroeder et al, 2008) and could also participate in the possible development of eating addiction. The endocannabinoid system is a key candidate to explore its involvement in this complex behavior through epigenetic, genetic, and pharmacological approaches due to its crucial role in the reward circuit and the pathogenesis of obesity (D'Addario et al, 2014). Epigenetic changes usually promote modifications in the expression of different proteins that can be evaluated by proteomic techniques.

These techniques offer the opportunity for assessing the entire expression, translation, modification of genes, and their expression products ( $\mathrm{Li}$ and Smit, 2008). In our study, proteomic analyses have been performed to identify proteins differentially expressed in mice vulnerable or not to addictive-like behavior in the hippocampus (HCP), striatum (ST), and prefrontal cortex (PFC). The use of proteomic studies is an essential tool for wide proteomic screening to explore global patterns of protein expression and also to identify markers of risk or protection of addictive-like disorders (Ortega et al, 2012).

The aim of the present study was to validate a mouse model of addictive-like behavior promoted by palatable food and to evaluate the differential epigenetic and protein expression changes induced by the development of this behavior in specific brain areas. Four brain regions closely related to addictive processes and overeating have been chosen: PFC, ST, nucleus accumbens (NAc), and HCP. The $\mathrm{PFC}$ regulates decision making and emotions and has been related to compulsive food intake disorders (Tomasi and Volkow, 2013). The ST is involved in driving the initial motivation for the different rewarding stimuli and has a crucial role in habit formation (Everitt et al, 2008). The NAc is a crucial structure in reward processes, including food- and drug-reinforcing effects (Everitt and Robbins, 2005), and the HCP is essential for memory, reward conditioning, and has a crucial role in food consumption relapse (Haber and Murai, 2006).

\section{MATERIALS AND METHODS}

\section{Animals}

Male CD1 mice (Charles River, France), weighing 30-32 g at the beginning of the first experiment were used. $\mathrm{CB}_{1} \mathrm{KO}$ mice and their wild-type littermates, weighing, respectively, 31-35 and 22-26g, were used in the second experiment (see Supplementary Information).

\section{Experimental Design}

In a first experiment, WT mice were divided in two groups trained in operant boxes with standard $(n=15)$ or chocolateflavored $(n=30)$ pellets. In the second experiment, $\mathrm{CB}_{1} \mathrm{KO}$ (Group 1, $n=11$ ) and WT mice (Group 2, $n=12$ and Group $3, n=15)$ were trained in operant boxes with chocolateflavored pellets. Animals were trained under a fixed-ratio (FR) 1 schedule of reinforcement in 1-h daily sessions during 5 days, followed by 113 (experiment 1) or 118 (experiment 2) days of training on a FR5 schedule. Every self-administration session was composed by $25 \mathrm{~min}$ of normal delivery of pellets (active period), followed by $10 \mathrm{~min}$ of non-reinforced active responses (pellets-free period), and 25 additional minutes of active period (Figure 1a). During the pellets-free period, no pellet reinforcer was delivered, signaled by the light that illuminated the entire box. A stimulus light, located above the active lever, was paired contingently with the delivery of the reward during the active periods. A time-out period of $10 \mathrm{~s}$ was established after each pellet delivery. During this period, the cue light was off and no reinforcer was provided after responding on the active lever. Responses on the active lever and all the responses performed during the time-out period were recorded. The beginning of each operant responding session was signaled by turning on a house light placed on the ceiling of the box only during the first $3 \mathrm{~s}$ of the session. The criteria for acquisition of operant responding were achieved when mice maintained a stable responding with $<20 \%$ deviation from the mean of the total number of food pellets earned in three consecutive sessions, with at least $75 \%$ responding on the reinforced lever, and a minimum of 10 reinforcers per session (Martin-Garcia et al, 2011).

Three addiction-like criteria of eating addiction model were evaluated at two different time points in each mouse, first during the early training sessions (1-18) and then during the late training sessions (days 105-113 experiment 1 ; days 110-118 experiment 2; Figure 1a). The experimental procedure was the same for experiments 1 and 2 until the day 105. From day 105, WT mice in experiment 2 were treated with vehicle (Group 3, $n=15$ ) or rimonabant (Group 
$2,3 \mathrm{mg} / \mathrm{kg}$, i.p. $n==12$ ) and tested for the three criteria of loss of control from day 110 to day 118 .

The score of food addiction criteria was attributed considering the responses obtained during the late training sessions using the following three behaviors resembling DSM-5 criteria for addiction: (1) persistence to response or difficulty to cut down of food seeking even if it is not available, measured by the persistence in active responding a

a EARLY TRAINING (1-18)

- Persistence to response

- Motivation

- Resistance to punishment

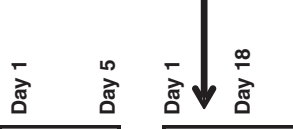

FR1

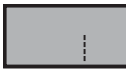

Daily setr.
LATE TRAINING (105-113/118)

- Persistence to response

- Motivation

- Resistance to punishment

Active Pellet-free Active

period period period

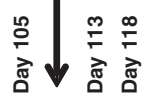

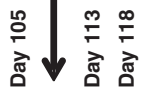

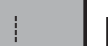

Group 2

$3 \mathrm{mg} / \mathrm{kg}$

Rimonabant

b

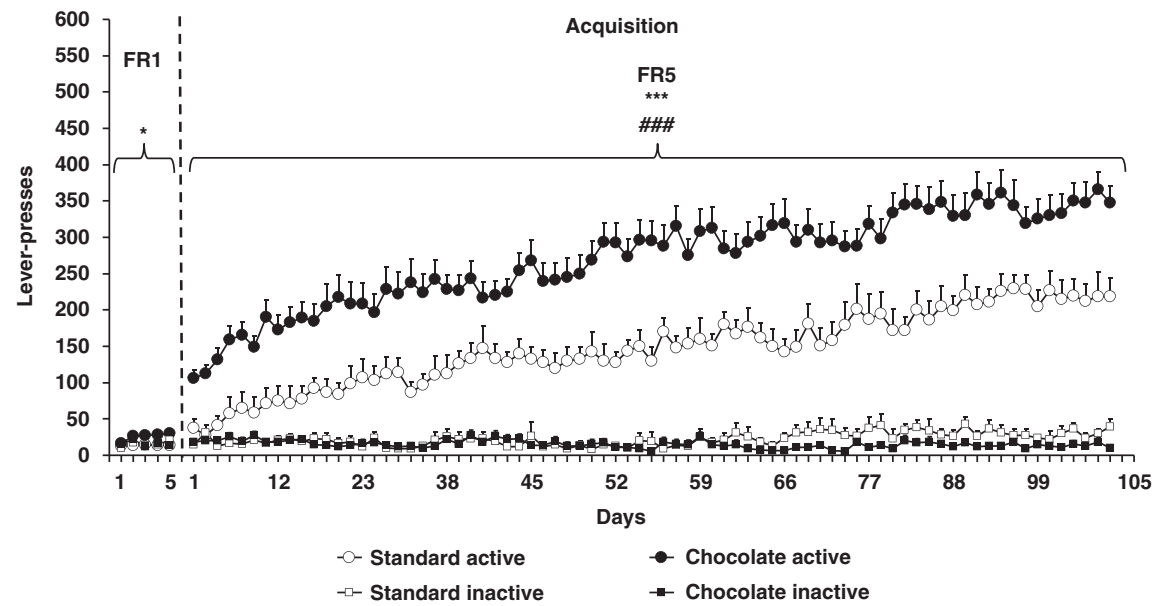

c

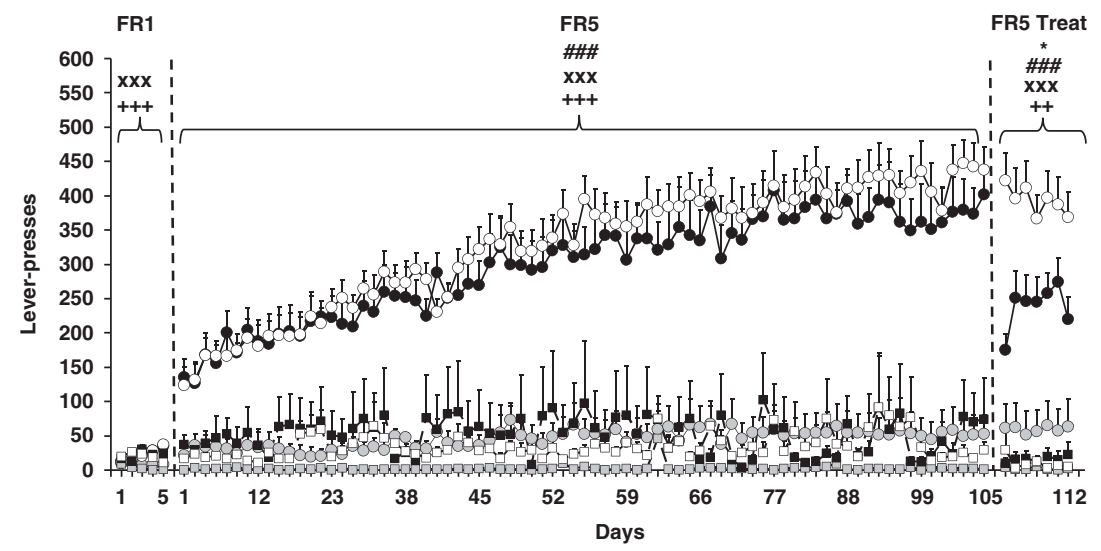

- Group 1 CB1 KO active

$\rightarrow$ Group 1 CB1 KO active

- Group 2 Veh (day1-105)-Rimonabant (day 106-112) active - Group 2 Veh (day1-105)-Rimonabant (day 106-112) active

$\rightarrow$ Group 3 Vehicle active

- Group 3 Vehicle active

d

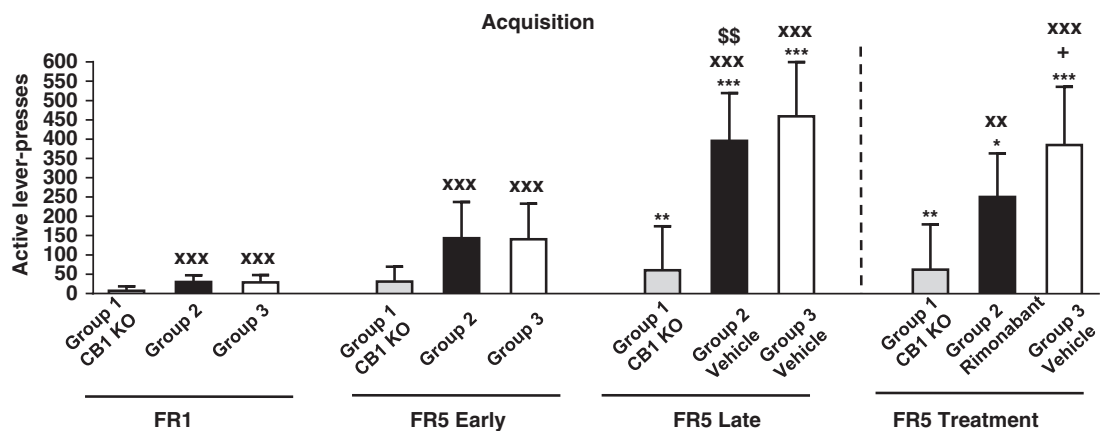


during the 10-min periods of signaled no food pellets availability, (2) high motivation for food pellets, measured by a progressive ratio (PR) schedule of reinforcement, and (3) resistance to punishment when food pellets use is maintained despite its negative consequences, measured by resistance to foot shock-induced punishment during operant responding maintained by food. This mouse model of food addictionlike behavior was adapted from that previously described for cocaine addiction in rats (Deroche-Gamonet et al, 2004).

Attribution of the three addiction-like criteria. The following behavioral tests were used to measure the criteria of eating addictive-like behavior:

Persistence to response. Responses for active leverpresses during the $10 \mathrm{~min}$ of unavailability of pellet delivery (pellets-free period) were measured as a persistence of foodseeking behavior. The active lever responses during the 10 min pellet-free period of the first 3 consecutive days of the early and late training period were evaluated.

Motivation. The PR schedule of reinforcement was used to evaluate the motivation for the food pellet during the early (days 6-13) and late (days 108-110 experiment 1 and days 113-115 experiment 2) period. The response required to earn the pellet escalated according to the following series: 1, 5, 12, $21,33,51,75,90,120,155,180,225,260,300,350,410,465$, $540,630,730,850,1000,1200,1500,1800,2100,2400,2700$, $3000,3400,3800,4200,4600,5000$, and 5500. The maximal number of responses that the animal performs to obtain one pellet is the last ratio completed, referred to as the breaking point. The maximum duration of the PR session was $5 \mathrm{~h}$ or until mice did not respond on any lever within $1 \mathrm{~h}$.

Resistance to punishment. Mice were placed for 1-day session in a self-administration chamber with a different kind of grid in the floor during the early (days 15-18) and late (days 111-113 experiment 1 and days 116-118 experiment 2) period. This environmental change acted as a contextual cue. The schedule was as follows: mice received an electric foot-shock $(0.20 \mathrm{~mA}, 2 \mathrm{~s})$ after four responses and received both, an electric foot-shock $(0.20 \mathrm{~mA}, 2 \mathrm{~s})$ and a pellet, associated with the corresponding conditioned stimulus (cue light), after the fifth response. The schedule was reinitiated at the end of the time-out period, ie, $10 \mathrm{~s}$ after the pellet delivery. If mice after the fourth response did not complete the fifth response within a minute, the sequence was reinitiated.

Supplementary Information includes extended experimental procedures with details of the apparatus, the procedure of operant responding maintained by food, and establishment of mice subpopulations. Description about the methods of sample preparation, epigenetic analysis, real-time qPCR (RT-qPCR), proteomic analysis, immunoblotting, and statistical analysis are also provided in the Supplementary Information.

\section{RESULTS}

\section{Acquisition of Operant Training Maintained by Food}

In experiment 1 , body weight was registered in mice trained with standard $(n=10,39.7 \pm 1.1 \mathrm{~g})$ or chocolate-flavored pellets $(n=27,40.9 \pm 0.5 \mathrm{~g})$ during the entire experiment, and no significant differences between groups were found $\left(F_{(1,35)}=0.18\right.$, NS). Both groups of mice underwent a FR1 schedule of reinforcement (5 days) followed by FR5 (113 days) (Figure 1a). Mice that did not achieve the acquisition criteria after day 33 were excluded from the study ( $n=5$ standard group and $n=3$ chocolate group). Three-way ANOVA revealed a significant interaction between 'group' and 'lever' during the acquisition of operant responding under FR1 $\left(\mathrm{F}_{(1,35)}=5.44, p<0.05\right.$; Figure 1b; Supplementary Information; Supplementary Table S2A), showing higher number of active responses in the chocolate than in the standard group. The acquisition criteria in FR5 were achieved after an average of $20.2 \pm 2.5$ sessions by $66.7 \%$ of mice trained with standard pellets and of $8.78 \pm 1.72$ sessions by $90 \%$ of mice trained with chocolate pellets. During FR5, three-way ANOVA revealed significant main effects of 'lever' $\left(\mathrm{F}_{(1,35)}=130.36, p<0.001\right)$, indicating a discrimination in all the groups and an interaction between 'group' and 'lever' $\left(\mathrm{F}_{(1,35)}=15.69, p<0.001\right)$, indicating higher number of active

Figure I (a) Experimental design. Experimental sequence of the eating addiction-like behavior model for the experiments I and 2, in which mice were trained for chocolate-flavored pellets or standard pellets (experiment I) under a fixed-ratio (FR) I schedule of reinforcement on I-h daily sessions during 5 days followed by I 3 days (experiment I) or I 8 days (experiment 2) on a FR5 schedule of reinforcement paired with the presentation of a cue light. Each session was composed by $25 \mathrm{~min}$ of normal delivery pellets named active period, followed by $10 \mathrm{~min}$ of pellets-free period in which the persistence to response was registered, and other 25 min of active period. In the FR5, two time points were considered, early and late period of the training, to measure the three addiction-like criteria: ( I) persistence to response, (2) motivation, and (3) resistance to punishment. The experimental procedure was the same for the experiments I and 2 until the day I05. From day I05, WT mice in experiment 2 were treated with vehicle (Group 3, n= I5) or rimonabant (Group 2; 3 mg/ kg, i.p. $n=12$ ) and tested for the three criteria of loss of control from day 110 to 1 I 8. (b) Acquisition of operant training maintained by food. Mean number of active and inactive lever-presses during the acquisition training in FRI and FR5 schedule of reinforcement in mice trained with standard pellets ( $n=10)$ and mice trained with chocolate-flavored pellets $(n=27)$. Differences are reported as mean \pm SEM. $* p<0.05$, **** $p<0.00$ I (chocolate group vs standard group); $\# \# \#<0.00$ I (active lever vs inactive lever). (c) Acquisition of operant training maintained by chocolate-flavored pellets. Mean number of active and inactive lever-presses during the acquisition training in FRI and FR5 schedule of reinforcement in $C B_{1} K O$ mice (Group I; $\left.n=I I\right)$, WT mice treated with rimonabant (3 mg/kg, i.p.) (Group 2; $n=12$ ) or vehicle (Group 3; $n=15$ ) and maintained by chocolate-flavored pellets. Differences are reported as mean \pm SEM. xxxp<0.05, (Group 3 vehicle vs Group | $\mathrm{CB}_{\mid} \mathrm{KO}$ ); ${ }^{++} p<0.01,{ }^{+++} p<0.00$ I (Group 2 rimonabant vs Group | CB, KO); ${ }^{*} p<0.05$, (Group I vehicle vs Group 2 rimonabant); ${ }^{\# \#} p<0.00$ I (active lever vs inactive lever). (d) Operant behavior to obtain chocolate-flavored pellets. Mean number of active leverpresses during the acquisition training in FRI schedule of reinforcement (day 3-5), FR5 early period (day I-3), FR5 late period (day I03- I05), and FR5 during the treatment (days IIO-II2) in $\mathrm{CB}_{1} \mathrm{KO}$ mice (Group I; $\left.n=1 \mathrm{I}\right)$, WT mice treated with rimonabant (3 mg/kg, i.p.) (Group 2; $n=12$,) or vehicle (Group 3; $n=15$ ). Differences are reported as mean \pm SEM. ${ }^{* *} p<0.05$, ${ }^{*} * * * t<<0.001$ (early period vs late period), ${ }^{x \times} p<0.01,{ }^{x \times x} p<0.00$ I (vs Group I); ${ }^{+} p<0.05$ (vs Group 2), and ${ }^{\$} p<0.01$ (Group 2 FR5 late vs Group 2 FR5 treatment). 
responses in the chocolate group (Figure 1b; Supplementary Information; Supplementary Table S2A).

In experiment 2, body weight was registered in $\mathrm{CB}_{1} \mathrm{KO}$ mice (Group 1; $n=11,39.12 \pm 1.20 \mathrm{~g}$ ), WT mice treated after day 105 with rimonabant $(3 \mathrm{mg} / \mathrm{kg}$, i.p.) (Group 2; $n=12$, $43.91 \pm 1.15 \mathrm{~g}$ ), or vehicle (Group 3; $n=15,47.91 \pm 1.03 \mathrm{~g}$ ). Significant differences between groups were reported $\left(\mathrm{F}_{(2,35)}=15.37, p<0.001\right)$ with $\mathrm{CB}_{1} \mathrm{KO}$ mice showing decreased body weight compared with vehicle $(p<0.001)$ and rimonabant $(p<0.05)$ treated mice. All the groups of mice underwent a FR1 schedule of reinforcement (5 days) followed by FR5 (105 days) and by an additional period of FR5 (7 days) in which WT mice were treated with rimonabant $(3 \mathrm{mg} / \mathrm{kg}$, i.p.) or vehicle (Figure 1a). Three-way ANOVA revealed a significant interaction between 'day', 'group', and 'lever' during the acquisition of operant responding under FR1 $\left(\mathrm{F}_{(1,8)}=3.07, p<0.005\right.$; Supplementary Information; Supplementary Table S2B). Subsequent post hoc analysis (Bonferroni) showed differences between groups (Figure $1 \mathrm{c}$ and $\mathrm{d}$ ), indicating that $\mathrm{CB}_{1} \mathrm{KO}$ mice performed less active lever-presses than the rest of the groups $(p<0.001)$. The acquisition criteria in FR5 were achieved after an average of $3.64 \pm 3.44$ sessions by $18.2 \%$ mice of $\mathrm{CB}_{1} \mathrm{KO}$ mice and after $10.4 \pm 3.02$ or $6.27 \pm 2.67$ sessions by $100 \%$ of the WT groups that will receive vehicle or rimonabant, respectively. During FR5, three-way ANOVA revealed significant main effects of 'day', 'group', and 'lever' $\left(\mathrm{F}_{(1,35)}=2.21, p<0.001\right)$, and subsequent post hoc analysis (Bonferroni) showed significant interactions between groups $(p<0.001)$; Figure 1c and d; (Supplementary Information; Supplementary Table S2B). During the 7 days of pharmacological treatment, three-way ANOVA revealed a significant interaction between 'day', 'group', and 'lever'. Subsequent post hoc analysis (Bonferroni) showed significant differences between $\mathrm{CB}_{1} \mathrm{KO}$ mice and mice treated with rimonabant $(3 \mathrm{mg} / \mathrm{kg}$, i.p., $p<0.05)$ or vehicle $(p<0.001)$ and between mice treated with vehicle and rimonabant $(p<0.05)$, indicating that rimonabant decreased the active leverpresses when compared with the control group and with the previous FR5 training period but to a lower extent than the $\mathrm{CB}_{1} \mathrm{KO}$ group (Figure $1 \mathrm{c}$ and $\mathrm{d}$ ) (Supplementary Information Supplementary Table S2B).

\section{Calculation of Addiction Score Based on the Three Addiction-Like Criteria and Distribution of Animals With Different Scores for Addiction-Like Behavior}

In experiment 1 , the two groups of animals were tested for the three behaviors used to evaluate the addiction-like criteria (persistence to response, motivation, resistance to punishment) during the early (days 1-18) and late (days 105-113) phases of the operant training. A mouse was considered positive for an addiction-like criterion when its score for each behavior was equal or major the 75th percentile of the distribution of chocolate group in the late period (Figure 2a-c). All animals were divided into four subgroups based on the number of criteria for which they scored (Figure 3a). During the early training period, $70 \%$ of mice trained with standard pellets presented 0 criteria, $20 \%$ reached 1 criteria, $10 \%$ showed 2 criteria, and $0 \%$ met the 3 criteria, while $40.7 \%$ of mice trained with chocolate pellets exhibited 0 criteria, $40.7 \%$ reached 1 criteria, $14.8 \% 2$ criteria, and $3.7 \%$ obtained the 3 criteria. During the late training period, $70 \%$ of mice trained with standard pellets presented 0 criteria, the remaining $30 \%$ only reached 1 criteria, and $0 \%$ showed 2 or 3 criteria (Figure 3b), whereas $55.6 \%$ of mice trained with chocolate pellets exhibited 0 criteria, $22.2 \%$ reached 1 criteria, $7.4 \%$ got 2 criteria, and $14.8 \%$ obtained the 3 criteria (Figure 3c). To confirm that the high score of addiction was reached only by the chocolate group and not by the standard pellet-trained group, the top quartile of this standard group was calculated considering the 75th percentile of the same standard group for the three behaviors resembling addiction. Results showed that none of the mice reached the 3 criteria. Indeed, $40 \%$ of mice trained with standard pellets presented 0 criteria in the late period, $50 \%$ obtained 1 criteria, $10 \%$ reached 2 criteria, and $0 \%$ showed the 3 criteria.

In experiment 2, all groups of animals were tested for the three behaviors used to evaluate the addiction-like criteria (persistence to response, motivation, and resistance to punishment) during the early (days 1-18) and late (days 110-118) phases of the operant training, as reported in experiment 1 (behavior was equal or major the 75th percentile of the distribution of vehicle-treated WT mice in the late period), (Figure $2 \mathrm{~d}-\mathrm{f}$ ). All animals were divided into four subgroups based on the number of criteria for which they scored (Figure 3d). In all, $91 \%$ of $\mathrm{CB}_{1} \mathrm{KO}$ mice trained with chocolate pellets presented 0 criteria and $9 \%$ reached 1 criteria, and the same distribution was obtained during the late training period (Figure $3 \mathrm{e}$ ). Moreover, $42 \%$ of WT mice trained with chocolate pellets that will receive later rimonabant presented 0 criteria, $42 \% 1$ criteria, and $17 \% 2$ criteria, while $60 \%$ of WT mice trained with chocolate pellets that will receive later the vehicle exhibited 0 criteria, $6.7 \%$ 1 criteria, $26.7 \% 2$ criteria, and $6.7 \% 3$ criteria. After rimonabant treatment during the late period, $67 \%$ of WT mice trained with chocolate reached 0 criteria, $25 \% 1$ criteria, and $8 \% 2$ criteria (Figure 3f), whereas $40 \%$ of WT mice treated with vehicle exhibited 0 criteria, $26.7 \% 1$ criteria, $20 \%$ 2 criteria, and $13.3 \% 3$ criteria (Figure $3 \mathrm{~g}$ ). Thus vehicletreated mice increased the percentage of mice reaching 3 criteria in the late period when compared with the early period, whereas rimonabant-treated mice decreased the percentage of animals reaching 1 and 2 criteria in the late period and none reached the 3 criteria in this group.

\section{Differences in Operant Responding Between the 0 and 2-3 Criteria Subgroups and Comparisons in Impulsivity- Like Behavior, Pellets Intake, and Body Weight}

In experiment 1 , three subgroups were selected for subsequent studies considering the data obtained during the late training period: (1) mice reaching $2-3$ criteria $(n=6)$, (2) 0 criteria $(n=6)$ in the chocolate group, and (3) 0 criteria $(n=6)$ in the standard group. In the persistence to response test (pellet-free period), standard pellets-trained mice presenting 0 criteria and chocolate-trained mice reaching the 2-3 criteria increased significantly the number of active lever-presses during the late training $(p<0.01)$; (Figure 4a). In the motivation test, only mice trained with chocolate pellets reaching the $2-3$ criteria significantly increased the breaking point during the late training $(p<0.05$; Figure $4 \mathrm{~b})$. In the resistance to punishment, only mice trained with 
a

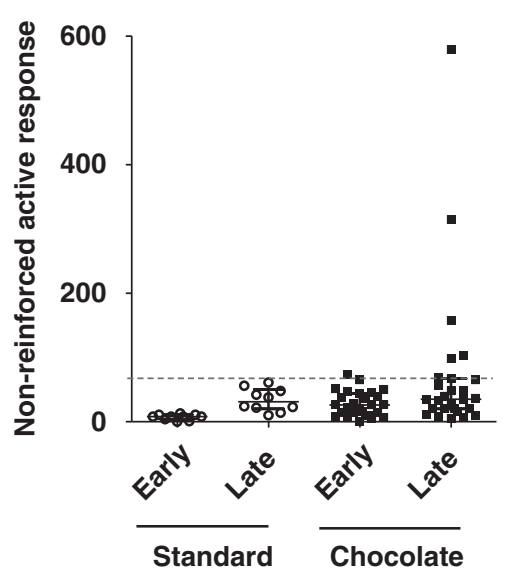

d

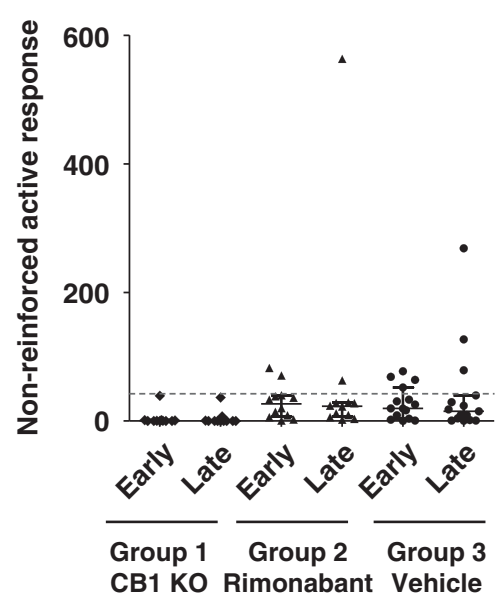

b

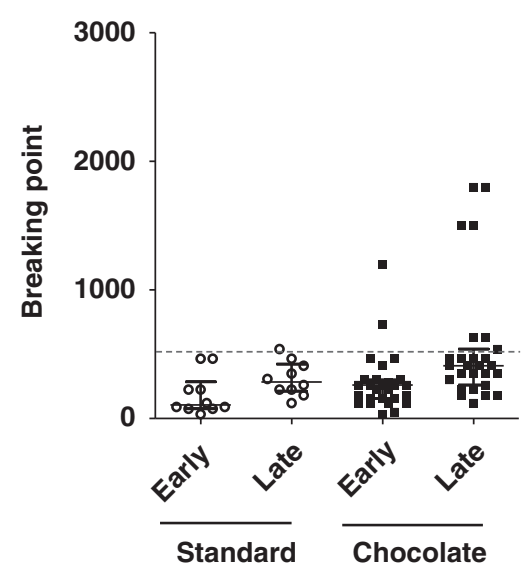

e

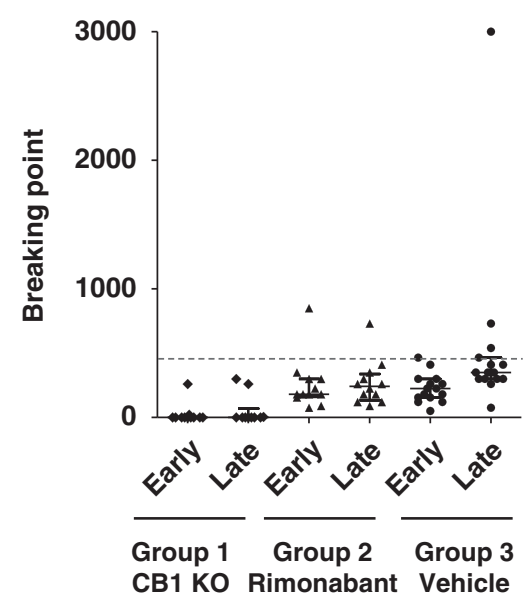

c

Resistance to punishment

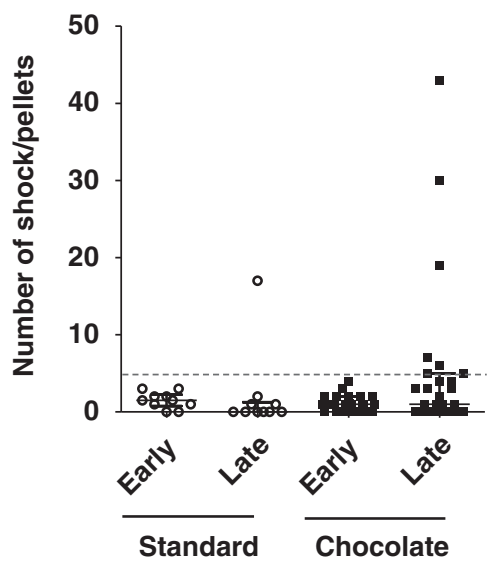

f

Resistance to punishment

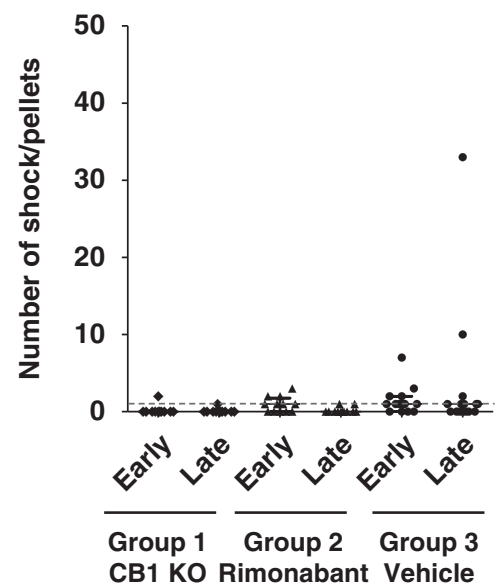

Figure 2 (a-f) Calculation of addiction score based on the three addiction-like criteria for the experiments I and 2. Distribution of individual data in the three tests used to measure addiction-like criteria during the early and late training of the (a-c) WT standard and chocolate group; ( $d-f)$ CB, KO mice (Group I; $n=1 \mathrm{I}$ ), WT mice treated with rimonabant (3 mg/kg, i.p.) (Group 2; $n=12$ ), or vehicle (Group 3; $n=15$ ) chocolate group calculated with median and interquartile range during the test of $(a, d)$ persistence to response, $(b, e)$ motivation, and $(c, f)$ resistance to punishment. The line indicates the 75 th percentile of distribution of $(\mathrm{a}-\mathrm{c}) \mathrm{WT}$ chocolate group during the late training period and $(\mathrm{d}-\mathrm{f}) \mathrm{WT}$ chocolate group treated with vehicle during the late training and is used as the criterion to attribute one point of the score to each individual located equal or above this percentile.

chocolate pellets reaching the $2-3$ criteria significantly increased the pellets intake during the foot-shock test $(p<0.05)$; (Figure 4c). The number of lever-presses during the time-out period was also evaluated as an indirect measure of impulsivity-like behavior. Mice trained with standard (0 criteria) and chocolate pellets reaching the 2-3 criteria significantly increased the number of active lever-presses during the time-out period in the late training $(p<0.01$; Figure $4 d$ ). Pearson correlation between time-out and pelletsfree period lever-presses in 2-3 criteria chocolate pelletstrained mice revealed the absence of correlation between both variables $(r=0.486 ; p=\mathrm{NS})$. This lack of correlation is not surprising considering that the behavioral responses during time-out period, thus after reaching a reward, should be different to those obtained during a signalled pellet-free period. Despite the differences between addiction-like scores groups, mice showing 0 and $2-3$ criteria did not significantly differ in the intake of high palatable chocolate pellets during the early and late operant training periods (Figure 4e) and had the same body weight (Figure 4f). Therefore, the differences in these two subgroups were not caused by variation in satiety or energy requirement.

In experiment 2, four subgroups of mice were selected according to the number of criteria attributed during the late training period: (1) 2-3 criteria WT mice treated with vehicle $(n=5),(2) 0$ criteria WT mice treated with vehicle $(n=5)$, (3) 0 criteria WT mice treated with rimonabant $(n=5)$, and (4) 0 criteria $\mathrm{CB}_{1} \mathrm{KO}$ mice $(n=5)$. In the persistence to response test (pellet-free period), 2-3 criteria WT mice treated with vehicle increased significantly active leverpresses during the late training when compared with 0 criteria WT mice treated with vehicle or rimonabant and $\mathrm{CB}_{1} \mathrm{KO}$ mice $(p<0.01)$. Moreover, 0 criteria WT mice treated with vehicle $(p<0.05)$ and rimonabant $(p<0.01)$ showed significant differences with respect to $\mathrm{CB}_{1} \mathrm{KO}$ mice (Figure $4 \mathrm{~g}$ ). In the motivation test, only WT mice treated 
a

Scoring of addiction-like behavior

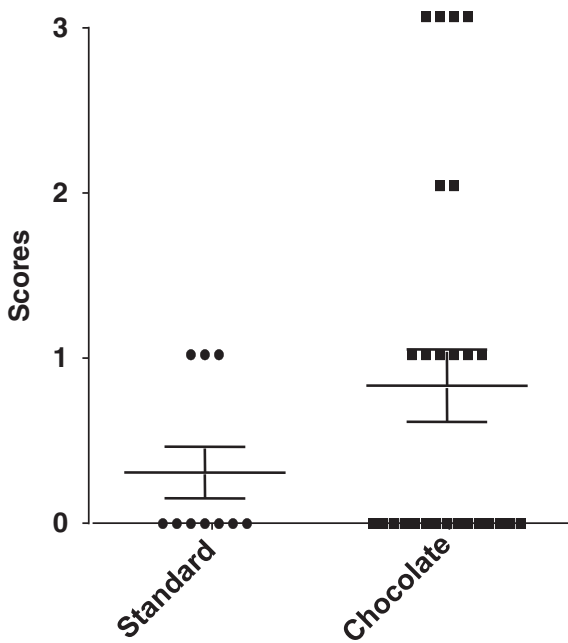

d

Scoring of addiction-like behavior

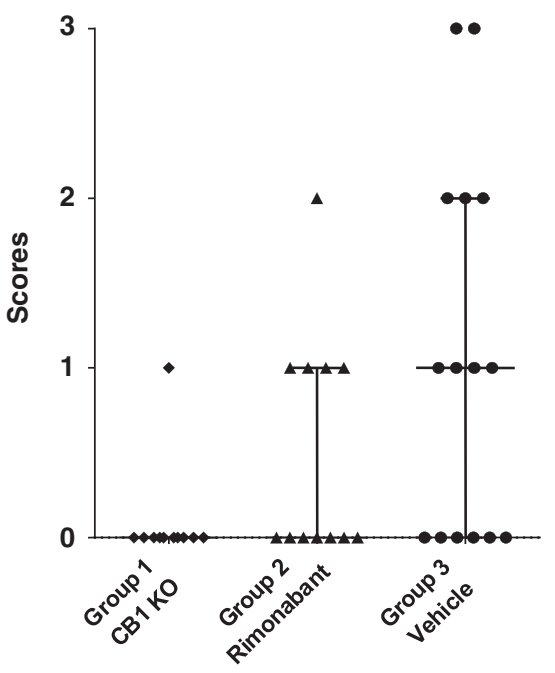

b Standard group
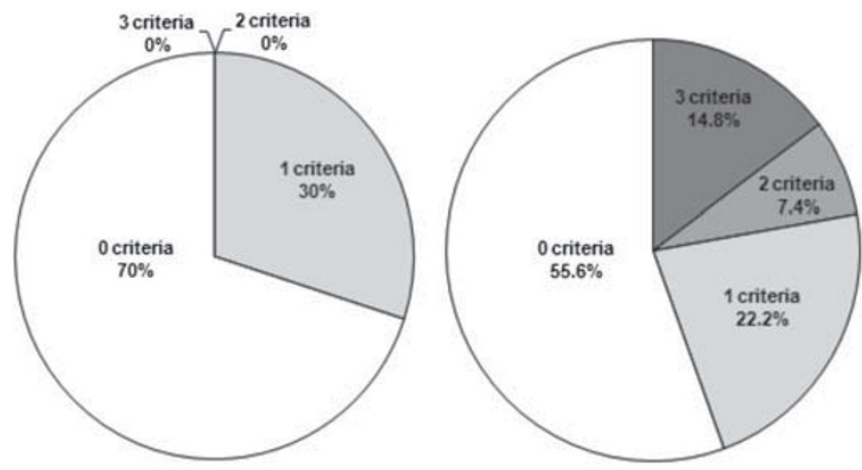

e

Group 1

CB1 KO

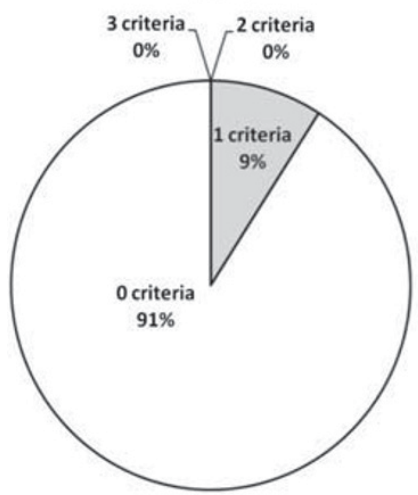

f

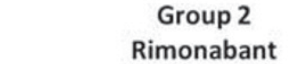

Rimonabant

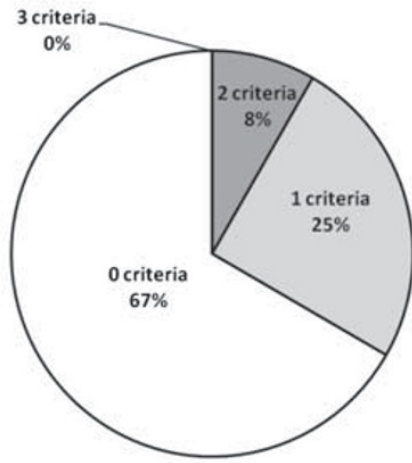

g Vehicle

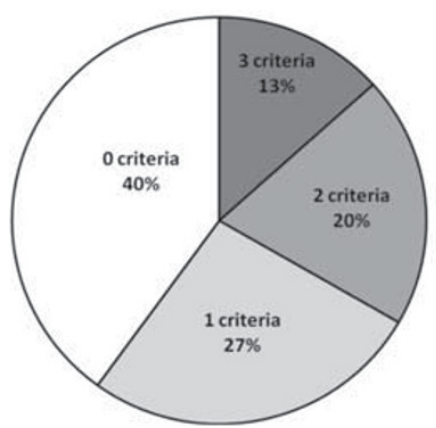

Figure 3 (a-d) Distribution of animals with different scores for addiction-like behavior. It was calculated as the algebraic sum of the scores obtained in each of the three addiction-like criteria. The addiction score was thus distributed along a scale from 0 to 3. Data are expressed with median and interquartile range. (b, c, e-g) Distribution of the different criteria subgroups in percentages. Animals were assigned to a criteria subgroup based on the amount of criteria met for which they scored equal or above the 75th percentile. (b) Percentage of distribution of the WT animals that were exposed to standard pellets, (c) percentage of distribution of WT animals that were exposed to high palatable chocolate-flavored pellets, (e) percentage of distribution of $C B_{1}, K O$ animals exposed to high palatable chocolate-flavored pellets, (f) percentage of distribution of WT animals treated with vehicle or rimonabant (3 mg/ $/ \mathrm{kg}$; i.p.) exposed to high palatable chocolate-flavored pellets, and (g) percentage of distribution of WT animals treated with vehicle exposed to high palatable chocolate-flavored pellets.

with vehicle reaching the $2-3$ criteria significantly increased the breaking point during the late training $(p<0.05)$ and showed significantly higher breaking point than vehicle $(p<0.05)$ or rimonabant $(p<0.01)$ WT mice reaching 0 criteria and $\mathrm{CB}_{1} \mathrm{KO}$ mice $(p<0.01$; Figure $4 \mathrm{~h})$. In the resistance to punishment, only WT vehicle-treated mice reaching 2-3 criteria significantly increased the pellets intake during the foot-shock test when compared with the different 
subgroups of 0 criteria $(p<0.01)$ (Figure 4i). In addition, mice treated with vehicle reaching $2-3$ criteria significantly increased the number of active lever-presses during the timeout period in the late training $(p<0.01)$ and showed significant differences with respect to the different 0 criteria subgroups $(p<0.05$ or $p<0.01$; Figure 41$)$. Finally, a significant increase of pellets intake during the late training period was only observed in 0 and $2-3$ criteria vehicletreated mice $(p<0.05$ and $p<0.01)$, whereas $\mathrm{CB}_{1} \mathrm{KO}$ mice decreased the pellets intake during this late period (Figure $4 \mathrm{~m}$ ). All groups of mice significantly increased the body weight during the late training $(p<0.05$ and $p<0.01)$, although this gain of weight was significantly higher in vehicle-treated WT mice then in WT mice treated with rimonabant and $\mathrm{CB}_{1} \mathrm{KO}$ mice (Figure $4 \mathrm{n}$ ).

\section{Epigenetic Analysis}

In the first experiment, specific DNA methylation at CNR1 gene promoter was analyzed by real-time methylation-specific PCR in PFC, ST, NAc, and HCP. In PFC, DNA methylation of CNR1 gene promoter region was decreased in mice reaching 2-3 criteria trained with chocolate pellets when compared with 0 criteria mice trained with standard pellets $\left(p<0.05\right.$; Figure 5a). No differences were reported in $\mathrm{CB}_{1}$ mRNA level, although a significant increase of $\mathrm{CB}_{1}$ protein expression was revealed in the PFC of mice trained with chocolate pellets reaching 2-3 criteria ( $p<0.01$; Figure $5 \mathrm{e}$ and i). In HCP, no significant differences were observed in DNA methylation at CNR1 gene promoter and a significant increase in $\mathrm{CB}_{1}$ gene expression was found in chocolatetrained mice with 2-3 criteria compared with mice trained with standard pellets (Figure 5b, $\mathrm{f}$, and $\mathrm{l}$ ), although no modification was revealed at the $\mathrm{CB}_{1}$ protein level. In NAc, no differences between the subgroups were reported in DNA methylation of CNR1 gene promoter, and a significant increase in $\mathrm{CB}_{1}$ mRNA level was shown when compared with 0 criteria standard pellets-trained mice and 2-3 criteria chocolate-trained mice, although this regulation did not lead to an increase of $\mathrm{CB}_{1}$ protein expression (Figure $5 \mathrm{c}, \mathrm{g}$, and $\mathrm{m}$ ). In $\mathrm{ST}$, no significant differences were observed in DNA methylation at the CNR1 gene promoter, $\mathrm{CB}_{1} \mathrm{mRNA}$ and protein levels (Figure 5d, h, and $\mathrm{n}$ ).

\section{Proteomic Analysis}

Proteomic profile was analyzed among the subgroups of the first experiment in HCP, ST, and PFC (see Supplementary Information).

\section{Immunoblotting}

Immunoblotting was performed to validate the most relevant changes obtained in the proteomic study in HCP, ST, and PFC (see Supplementary Information).

\section{DISCUSSION}

We have validated a novel operant model of eating addictivelike behavior in a heterogenic population of mice exposed to long-term operant training to obtain palatable food. This model permits to distinguish different subpopulations of mice vulnerable $(22.2 \%)$ or resistant $(55.6 \%)$ to addiction. Several changes in gene and protein expression were identified in the mouse subpopulations in PFC, HCP, NAc, and ST through epigenetic and proteomic studies. Using genetic and pharmacological approaches, we demonstrated the crucial involvement of $\mathrm{CB}_{1}$ receptor in the development of this addictive-like behavior.

Food palatability strongly promoted operant seekingbehavior in our experimental conditions. Thus mice trained with chocolate-flavored pellets increased their operant active responses during FR1 and FR5 schedule more than animals trained with standard pellets. The percentage of chocolatetrained mice that achieved the acquisition criteria was higher and in a shorter duration time ( $90 \%$ in 8 sessions) than in standard pellets-trained mice $(66.7 \%$ in 20 sessions). A differential response depending on the kind of pellets was also revealed when testing for the three criteria of loss of behavioral control that mimic addictive-like behavior. Indeed, $14.7 \%$ of mice trained with chocolate pellets reached in the late training period the 3 criteria and $7.4 \%$ achieved 2 criteria, whereas none of the mice trained with standard pellets achieved these criteria. These mice with high scores also revealed increased operant responses even when no reward can be obtained during the time-out period, suggesting an enhancement of food seeking that can be related to increased impulsivity. The identification of this subgroup of mice losing behavioral control supports the hypothesis that addiction-like behavior represents a pathological continuum from controlled to compulsive use that is only reached by a limited percentage of users (Piazza and Deroche-Gamonet, 2013). Experiments performed in rodents also using the three criteria of loss of control of operant seeking to obtain a drug of abuse (cocaine) revealed a higher percentage of animals reaching these criteria $(17.2 \%$ 3 criteria and $13.8 \% 2$ criteria); (Deroche-Gamonet et al, 2004). This could be due to the different behavioral responses promoted by natural rewards and drugs of abuse, as well as by the different animal species (rats and mice) and experimental conditions required to achieve these distinct experiments. Considering the strict criteria defined in our protocol to achieve a loss of control of a natural reward seeking in mice and the difficulties to accomplish a complex operant responding in these animal species, we have established that mice achieving 2 and 3 criteria (22.2\%) have reached a reliable loss of control of this behavioral response. This percentage is similar to those reported in other studies using operant responding to obtain drugs of abuse and allow obtaining a minimum amount of biological samples from the mouse brains to achieve the subsequent epigenetic and proteomic analysis. Only mice reaching the high and low score were selected for the subsequent studies. None of the mice of the standard pellet group reached the $2-3$ criteria. The lack of standard pellets mice reaching these criteria could represent a potential limitation in the interpretation of proteomic and epigenetic data as comparisons between the chocolate 2-3 criteria and standard 2-3 criteria groups could not be performed.

Long-term operant training to obtain highly palatable food produced adaptive changes at the epigenetic level. Mice that reach the 2-3 criteria showed a significant reduction in DNA methylation at CNR1 gene promoter in PFC, which led to an upregulation of CNR1 gene expression and the subsequent increase in $\mathrm{CB}_{1}$ protein receptor in the same brain area. The 
increased level of $\mathrm{CB}_{1}$ protein may be due to multiple factors that are involved in gene transcription and protein synthesis, including methylation of the gene promoter. Differential changes were also observed in the CNR1 gene expression in the NAc and HCP of the addict-like mice, although these regulations could not be functionally relevant as no modification was revealed at the $\mathrm{CB}_{1}$ protein level, the ending product through which the genetic information determines cellular functions.
$\mathrm{CB}_{1}$ receptors has a crucial role in the reinforcing and motivational properties of highly palatable food (Maccioni et al, 2008). Indeed, $\mathrm{CB}_{1} \mathrm{R}$ modulates the glutamatergic excitatory and GABAergic inhibitory synaptic inputs in several brain regions, acting as a regulatory feedback mechanism to modulate synaptic transmission (D'Addario et al, 2014). Previous studies proposed a bimodal regulation of food intake by $\mathrm{CB}_{1} \mathrm{R}$ in cortical glutamatergic transmission, responsible for the orexigenic effect, and $\mathrm{CB}_{1} \mathrm{R}$ in a
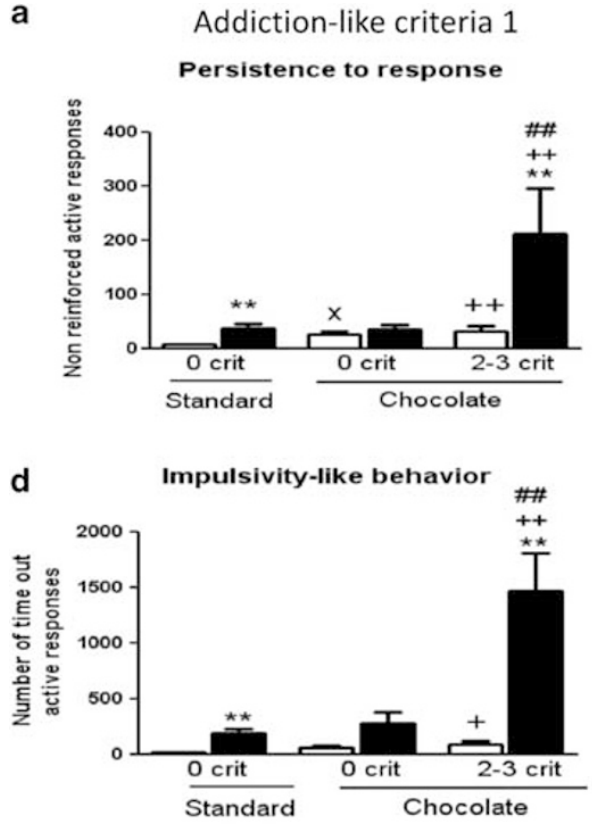

g

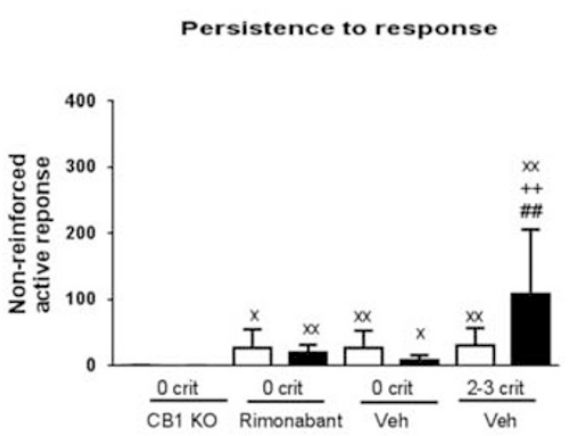

I

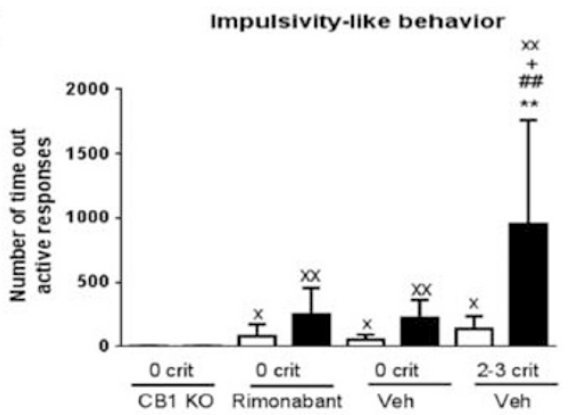

b

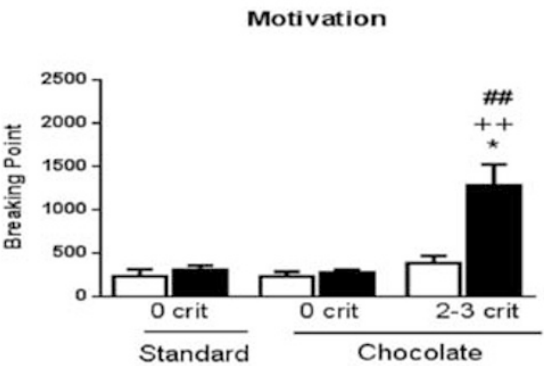

e

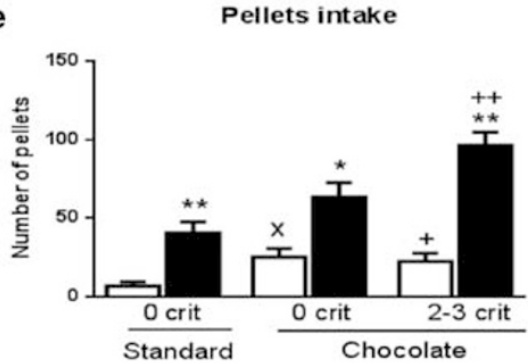

h

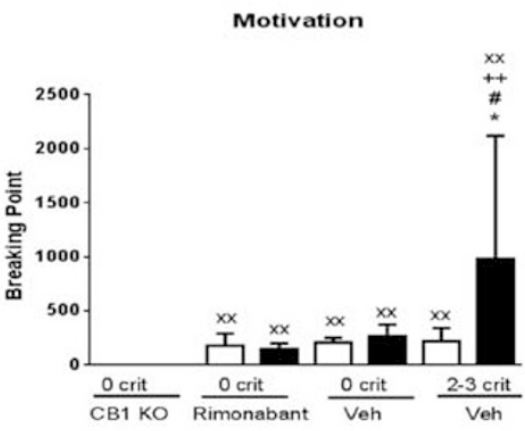

m

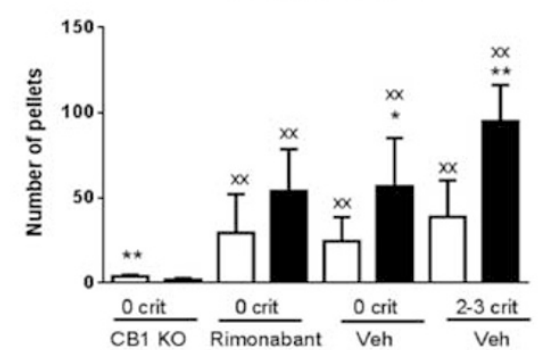

c

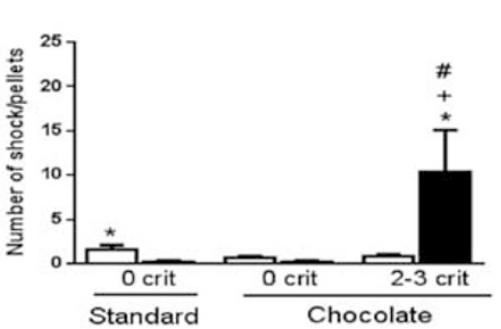

f

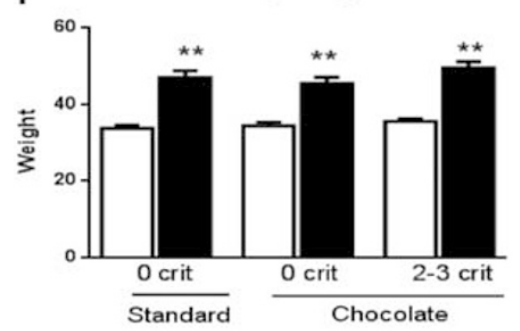

i

Resistance to punishment

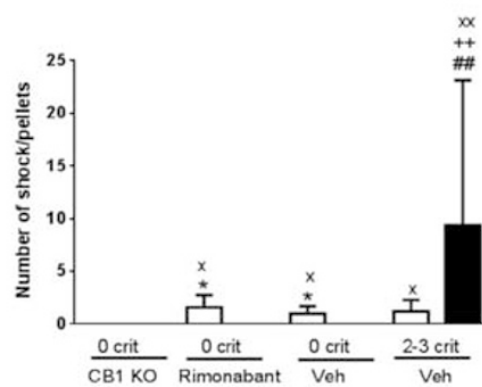

n

Body weight

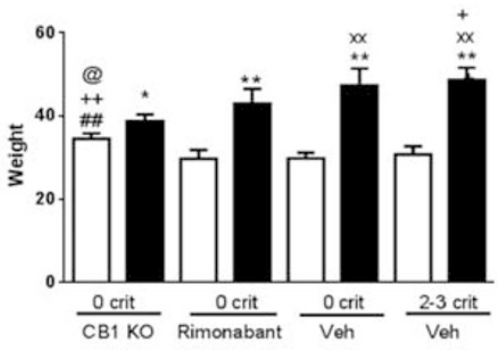


ventrostriatal GABAergic neurons, mediator of the hypophagic action by reducing local inhibitory transmission (Bellocchio et al, 2010). We hypothesized that the $\mathrm{CB}_{1} \mathrm{R}$ epigenetic regulation in $\mathrm{PFC}$ and the subsequent translation in increased $C_{1}$ protein level found in our study may modulate the primary glutamatergic neuronal output of this region, as already described in other studies (Steketee, 2003). $\mathrm{CB}_{1} \mathrm{R}$ on cortical glutamatergic cells are less abundant but produce more pronounced effects than on GABAergic cells (Steindel et al, 2013). Specifically, the decrease in DNA methylation at CNR1 gene could promote an upregulation of $\mathrm{CB}_{1} \mathrm{R}$ on glutamatergic projection terminals leading to a $\mathrm{CB}_{1}$-dependent inhibition of excitatory glutamatergic transmission that promotes food intake. This CB1R overexpression on glutamatergic projections could decrease glutamate release in the NAc contributing to a less activation of the NAc GABAergic inputs to VTA, removing the inhibitory modulation on Da neurons, as already reported (Lupica et al, 2004; Melis et al, 2004). Hence, $\mathrm{CB}_{1} \mathrm{R}$ acting indirectly via presynaptic inhibition of neurons and interneurons (Szabo et al, 2002) may ultimately affect brain reward processes through their ability to enhance extracellular DA levels in the NAc (Fadda et al, 2006; Lecca et al, 2006).

We have performed pharmacological studies with a selective $\mathrm{CB}_{1}$ receptor antagonist and genetic approaches with constitutive $\mathrm{CB}_{1}$ knockout mice to evaluate our hypothesis about the involvement of $\mathrm{CB}_{1}$ receptor in the development of this addictive-like behavior produced by palatable food. The pharmacological treatment with the $\mathrm{CB}_{1}$ receptor antagonist rimonabant $(3 \mathrm{mg} / \mathrm{kg})$ at the beginning of the late training period reduced the percentage of mice that reached addiction scores. Thus none of rimonabanttreated mice reached the 3 criteria, whereas $67 \%$ of treated mice achieved 0 criteria. In contrast, $13 \%$ of vehicle-treated mice reached the 3 criteria and $20 \%$ achieved 2 criteria, similarly to the previous experiment although the responses in the three behavioral tests were decreased with respect to the previous experiment as expected considering the stressor event that represents the repeated intraperitoneal injection. These results supports the hypothesis that $\mathrm{CB}_{1}$ receptors are involved in the achievement of addiction-like behavior, thus in the transition to addiction that evolves from controlled to compulsive intake. In agreement, deletion of $\mathrm{CB}_{1}$ receptors in constitutive $\mathrm{CB}_{1} \mathrm{KO}$ mice reduced operant seeking behavior in our experimental conditions. Thus $\mathrm{CB}_{1} \mathrm{KO}$ mice trained with chocolate-flavored pellets significantly reduced operant active responses during FR1 and FR5 compared with WT mice. The percentage of $\mathrm{CB}_{1} \mathrm{KO}$ mice that reached addiction criteria in the late period was significantly lower than WT mice, and none of $\mathrm{CB}_{1} \mathrm{KO}$ mice reached the 3 or 2 criteria in the late training period. These $\mathrm{CB}_{1} \mathrm{KO}$ mice also showed decreased operant responses during the time-out period, which can be related to a lack of impulsivity. Therefore, the pharmacological or genetic disruption of $\mathrm{CB}_{1}$ receptor activity reduced the reinforcing effect of palatable food and prevented the transition to addiction. Future studies are needed to elucidate the functional and structural interactions between $\mathrm{CB}_{1}$ receptors and the main neurotransmitter system in the context of eating addiction.

Proteomic studies have revealed changes in the protein expression and in the level of phosphorylation of synaptic proteins depending on the experimental subgroup and the brain area analyzed. These proteomic data were compared with previous studies with drugs of abuse in order to identify similar molecular targets underlying addictive-like behaviors. Protein expression profiles were compared in the three brain regions studied and specific common proteins related to impulsive-like behavior, synaptic plasticity, and cannabinoid signaling that could promote neurobiological changes leading to eating addiction-like behavior were selected and validated by immunoblot technique: $\alpha$-Syn (impulsive control: Ambermoon et al, 2011), PP1 $\alpha$, DCalmK 2, (synaptic plasticity processes: Edelman et al, 2005; Hou et al, 2013), and DGK $\zeta$ (regulation of the endocannabinoid activity: Liu et al, 2001). An overexpression of $\alpha$-Syn was revealed in the HCP of mice trained with chocolate pellets reaching the 2-3 criteria and in the PFC of mice trained with chocolate pellets presenting 0 criteria, which could facilitate impulsivity-like behavior. In agreement, a similar increase of $\alpha$-Syn expression in the HCP was reported in cocaineaddicted rats (Brenz Verca et al, 2003). $\alpha$-Syn is a neuronal protein regulating dopaminergic transmission (Boyer and Dreyer, 2007) involved in synaptic vesicular transport and

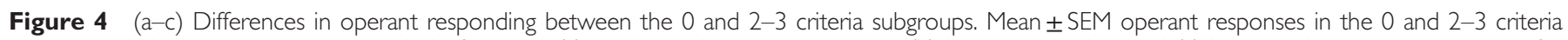

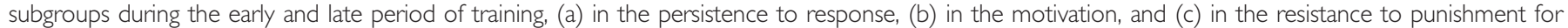

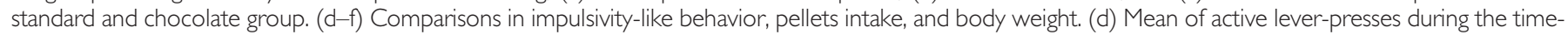
out period during the 3 consecutive day sessions in the early and late operant training periods for the standard subgroup and chocolate subgroups ( 0 criteria

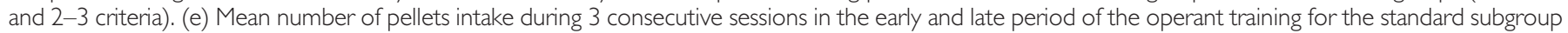
and chocolate subgroups ( 0 criteria and 2-3 criteria). ( $f$ ) Mean of body weight during the early and late periods of the operant training for the standard

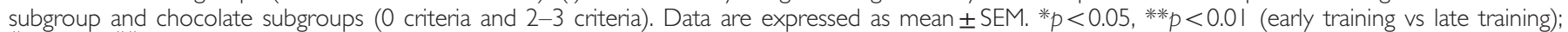

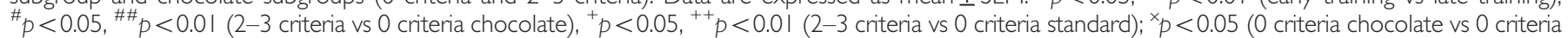

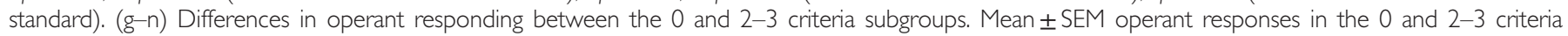

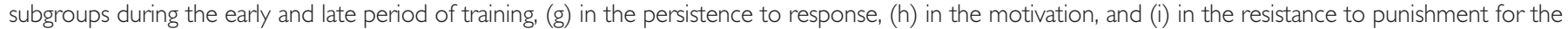

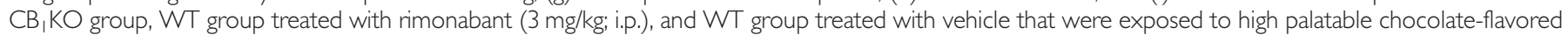

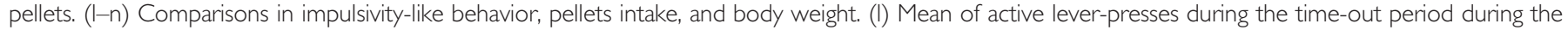

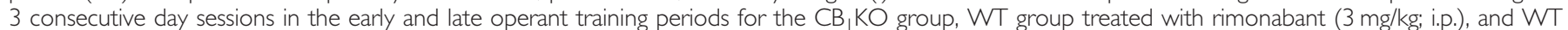

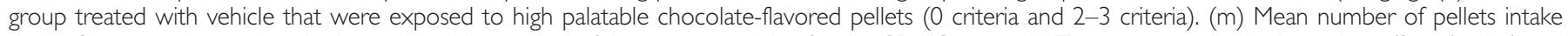

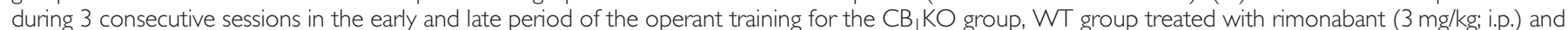

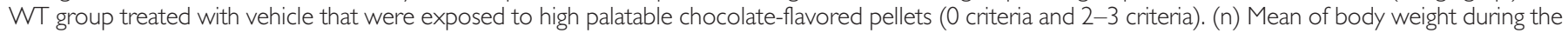

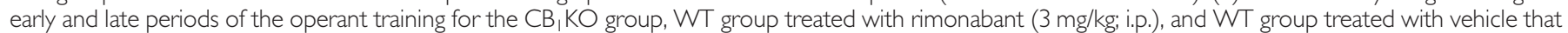

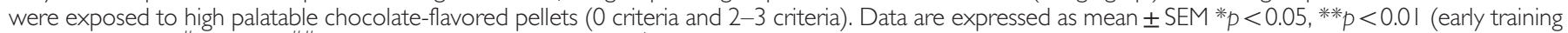

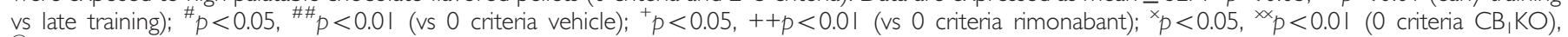
$@_{p}<0.05$ (vs 2-3 criteria vehicle). 

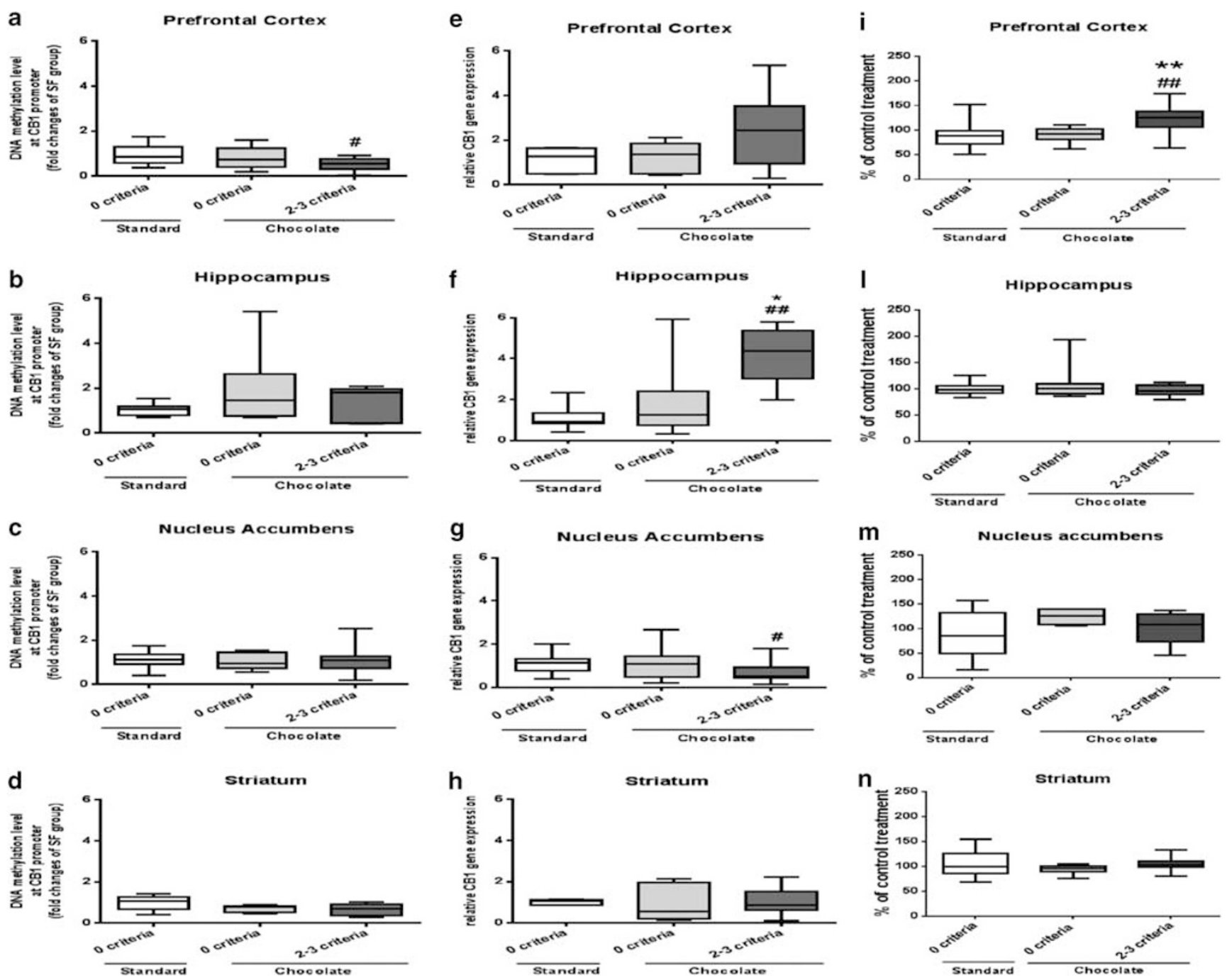

Figure $5 \quad C B$, epigenetic regulation through DNA methylation at its $C N R /$ gene promoter, $C N R /$ gene expression, and $C B_{\text {| }}$ protein levels in eating addiction like-behavior. (a-d) Level of DNA methylation in the (a) prefrontal cortex, (b) hippocampus, (c) striatum, and (d) nucleus accumbens. (e-h) CNR I gene expression regulation in the (e) prefrontal cortex, ( $f$ ) hippocampus, (g) striatum, and (h) nucleus accumbens. (i-n) Quantification of CB, protein levels in the (i) prefrontal cortex, (I) hippocampus, (m) striatum, and (n) nucleus accumbens. The optical density was normalized to GAPDH in the same samples. Data are reported as a fold change of standard subgroup; ${ }^{*} p<0.05,{ }^{\# \#} p<0.01$ (vs mice 0 criteria standard pellets); ${ }^{*} p<0.05, * * * 0.01$ (vs mice 0 criteria chocolate pellets).

synaptic plasticity (Murphy et al, 2000) and has been implicated in impulsive control disorders, such as drug addiction (Pena-Oliver et al, 2012). In contrast, a decreased expression of the same protein was found in the ST of mice trained with standard pellets that leads to speculate impairment in dopaminergic neurotransmission. Indeed, $\alpha$ Syn-deficient mice exhibited dopaminergic hyperactivity and a reduction in presynaptic striatal DA store (Abeliovich et al, 2000; Senior et al, 2008).

A downregulation of $\mathrm{PP} 1 \alpha$ expression in HCP and an upregulation in ST was observed in chocolate-trained mice reaching the 2-3 criteria, while no modifications were reported in PFC. This protein localized in excitatory synapses is involved in synaptic plasticity (Hou et al, 2013) and seems to be important for triggering long-term depression (LTD) through the dopamine-induced phosphorylation of DARPP-32 (Yan et al, 1999). PP1 $\alpha$ overexpression in the ST of mice reaching the highest criteria could induce
LTD as PP1 is crucial for maintaining NMDAR-dependent LTD (Mulkey et al, 1993). The opposite regulation of PP1 $\alpha$ expression in HCP and ST could modify synaptic strength leading to the plasticity changes promoted by palatable food training.

Palatable food training increased the expression of DCalmK 2 in mice reaching the 2-3 criteria and 0 criteria in the HCP and ST, respectively, whereas no modifications were reported in the PFC. DCalmK 2 is a protein localized in the distal dendrites that suppresses the maturation of spine structures (Shin et al, 2013), covering an important role in the regulation of synaptic plasticity (Edelman et al, 2005). The increased expression of the DCalmK 2 protein after long-term exposure to chocolate pellets may therefore regulate the maturation of dendritic spines and synaptic plasticity.

An overexpression of $\mathrm{DGK} \zeta$ protein was selectively observed in the HCP and ST of chocolate-trained mice with 
0 criteria. DGK $\zeta$ modules subcellular levels of diacylglycerol and phosphatidic acid, as well the synthesis of triacylglycerols (Topham and Epand, 2009). Previous research demonstrated that high-fat diet stimulated DGK $\zeta$ expression in hypothalamus, and this expression was reduced in obese animals being inversely related to body fat mass and serum leptin level (Liu et al, 2001). Furthermore, DGK $\zeta$ seems to modulate the cannabinoid signaling (Gantayet et al, 2011) and could lead to hypothesize an inversely expression regulation between DGK $\zeta$ and CB1R in specific brain areas under our experimental conditions.

In conclusion, our research validated for the first time an operant model of eating addiction in a heterogenic mouse population and identified extreme subpopulations vulnerable or resistant to addiction. We detected in these subpopulations specific epigenetic and proteomic alterations in the HCP, ST, NAc, and PFC. Changes in DNA methylation at CNR1 gene promoter and its encoding transcript were observed in the PFC. The involvement of these changes in $\mathrm{CB}_{1} \mathrm{R}$ in the development of this addictive-like behavior was demonstrated by using genetic and pharmacological approaches. Moreover, we identified proteins expressed in different subpopulations of mice that have allowed formulating novel hypotheses on the molecular mechanisms orchestrating eating addiction. These changes could participate in the biological substrate underlying the behavioral alterations that could eventually lead to eating-related disorders and provide an important advance in understanding the mechanisms engaged in the hedonic aspects of food consumption furthering eating addiction.

\section{FUNDING AND DISCLOSURE}

This work was supported by the DG Research of the European Commission FP7 (No. HEALTH-F2 2013-602891), the Spanish 'RETICS-Instituto de Salud Carlos III' (No. RD12/0028/0023), the Spanish 'Ministerio de Ciencia e Innovación' (No. SAF2011-29864), and the Catalan Government 'AGAUR-Generalitat de Catalunya' (Nos. 2009SGR00731 and 2014-SGR-1547). The FEDER funds support is also acknowledged. SM and AB were supported by FI predoctoral fellowships of the Catalan Government, and JG-C was supported by a 'Juan de la Cierva' postdoctoral fellowship from the Spanish 'Ministerio de Ciencia e Innovación'. Also support by the Italian Ministry of University and Research under grants FIRB-RBFR12DELS to CDA and PRIN2010-11 to MM is gratefully acknowledged. The authors declare no conflict of interest.

\section{ACKNOWLEDGMENTS}

We thank Dr Andrés Ozaita for invaluable technical assistance, and Sami Kummer for his help in the behavioral studies.

\section{REFERENCES}

Abeliovich A, Schmitz Y, Farinas I, Choi-Lundberg D, Ho WH, Castillo PE et al (2000). Mice lacking alpha-synuclein display functional deficits in the nigrostriatal dopamine system. Neuron 25: $239-252$.
Ambermoon P, Carter A, Hall WD, Dissanayaka NN, O'Sullivan JD (2011). Impulse control disorders in patients with parkinson's disease receiving dopamine replacement therapy: evidence and implications for the addictions field. Addiction 106: 283-293.

Bellocchio L, Lafenetre P, Cannich A, Cota D, Puente N, Grandes P et al (2010). Bimodal control of stimulated food intake by the endocannabinoid system. Nat Neurosci 13: 281-283.

Boyer F, Dreyer JL (2007). Alpha-synuclein in the nucleus accumbens induces changes in cocaine behaviour in rats. Eur $J$ Neurosci 26: 2764-2776.

Brenz Verca MS, Bahi A, Boyer F, Wagner GC, Dreyer JL (2003). Distribution of alpha- and gamma-synucleins in the adult rat brain and their modification by high-dose cocaine treatment. Eur J Neurosci 18: 1923-1938.

Brownell KD (2004). Obesity and managed care: a role for activism and advocacy? Am J Manag Care 10: 353-354.

Curtis C, Davis C (2014). A qualitative study of binge eating and obesity from an addiction perspective. Eat Disord 22: 19-32.

D'Addario C, Micioni Di Bonaventura MV, Pucci M, Romano A, Gaetani S, Ciccocioppo R et al (2014). Endocannabinoid signaling and food addiction. Neurosci Biobehav Rev 47C: 203-224.

Deroche-Gamonet V, Belin D, Piazza PV (2004). Evidence for addiction-like behavior in the rat. Science 305: 1014-1017.

Edelman AM, Kim WY, Higgins D, Goldstein EG, Oberdoerster M, Sigurdson W (2005). Doublecortin kinase-2, a novel doublecortin-related protein kinase associated with terminal segments of axons and dendrites. J Biol Chem 280: 8531-8543.

Everitt BJ, Belin D, Economidou D, Pelloux Y, Dalley JW, Robbins TW (2008). Review. Neural mechanisms underlying the vulnerability to develop compulsive drug-seeking habits and addiction. Philos Trans $R$ Soc Lond B Biol Sci 363: 3125-3135.

Everitt BJ, Robbins TW (2005). Neural systems of reinforcement for drug addiction: from actions to habits to compulsion. Nat Neurosci 8: 1481-1489.

Fadda P, Scherma M, Spano MS, Salis P, Melis V, Fattore L et al (2006). Cannabinoid self-administration increases dopamine release in the nucleus accumbens. Neuroreport 17: 1629-1632.

Gallup (2014). Http://www.Gallup.Com/Poll/170264/Adult-ObesityRate.Aspx.

Gantayet A, Jegatheswaran J, Jayakumaran G, Topham MK, Epand RM (2011). Endocannabinoids and diacylglycerol kinase activity. Biochim Biophys Acta 1808: 1050-1053.

Gearhardt AN, Boswell RG, White MA (2014). The association of "food addiction" with disordered eating and body mass index. Eat Behav 15: 427-433.

Gearhardt AN, Roberto CA, Seamans MJ, Corbin WR, Brownell KD (2013). Preliminary validation of the yale food addiction scale for children. Eat Behav 14: 508-512.

Gearhardt AN, White MA, Potenza MN (2011). Binge eating disorder and food addiction. Curr Drug Abuse Rev 4: 201-207.

Haber M, Murai KK (2006). Reshaping neuron-glial communication at hippocampal synapses. Neuron Glia Biol 2: 59-66.

Hebebrand J, Albayrak O, Adan R, Antel J, Dieguez C, de Jong J et al (2014). "Eating addiction", rather than "food addiction", better captures addictive-like eating behavior. Neurosci Biobehav Rev 47C: 295-306.

Heber D, Carpenter CL (2011). Addictive genes and the relationship to obesity and inflammation. Mol Neurobiol 44: 160-165.

Hou H, Sun L, Siddoway BA, Petralia RS, Yang H, Gu H et al (2013). Synaptic NMDA receptor stimulation activates PP1 by inhibiting its phosphorylation by Cdk5. J Cell Biol 203: 521-535.

Jaenisch R, Bird A (2003). Epigenetic regulation of gene expression: how the genome integrates intrinsic and environmental signals. Nat Genet 33: 245-254. 
Lecca D, Cacciapaglia F, Valentini V, Di CG (2006). Monitoring extracellular dopamine in the rat nucleus accumbens shell and core during acquisition and maintenance of intravenous WIN 55,212-2 self-administration. Psychopharmacology (Berl) 188: 63-74.

Li KW, Smit A B (2008). Subcellular proteomics in neuroscience. Front Biosci 13: 4416-4425.

Liu Z, Chang GQ, Leibowitz SF (2001). Diacylglycerol kinase zeta in hypothalamus interacts with long form leptin receptor. Relation to dietary fat and body weight regulation. J Biol Chem 276: 5900-5907.

Lupica CR, Riegel AC, Hoffman AF (2004). Marijuana and cannabinoid regulation of brain reward circuits. $\mathrm{Br} J$ Pharmacol 143: 227-234.

Maccioni P, Pes D, Carai MA, Gessa GL, Colombo G (2008). Suppression by the cannabinoid cb1 receptor antagonist, rimonabant, of the reinforcing and motivational properties of a chocolateflavoured beverage in rats. Behav Pharmacol 19: 197-209.

Martin-Garcia E, Burokas A, Kostrzewa E, Gieryk A, Korostynski M, Ziolkowska B et al (2011). New operant model of reinstatement of food-seeking behavior in mice. Psychopharmacology (Berl) 215: 49-70.

Melis M, Pistis M, Perra S, Muntoni AL, Pillolla G, Gessa GL (2004). Endocannabinoids mediate presynaptic inhibition of glutamatergic transmission in rat ventral tegmental area dopamine neurons through activation of CB1 receptors. J Neurosci 24: 53-62.

Mulkey RM, Herron CE, Malenka RC (1993). An essential role for protein phosphatases in hippocampal long-term depression. Science 261: 1051-1055.

Murphy DD, Rueter SM, Trojanowski JQ, Lee VM (2000). Synucleins are developmentally expressed, and alpha-synuclein regulates the size of the presynaptic vesicular pool in primary hippocampal neurons. J Neurosci 20: 3214-3220.

Ortega M, Calva Nieves J, Zamora A, Gelman P, Palma B (2012). Addictions, genomics and proteomics. Salud Ment 35 no.2, pp 129-137.

Pena-Oliver Y, Buchman VL, Dalley JW, Robbins TW, Schumann G, Ripley TL et al (2012). Deletion of alpha-synuclein decreases impulsivity in mice. Genes Brain Behav 11: 137-146.

Piazza PV, Deroche-Gamonet V (2013). A multistep general theory of transition to addiction. Psychopharmacology (Berl) 229: 387-413.

Pretlow RA, Stock CM, Allison S, Roeger L (2015). Treatment of child/adolescent obesity using the addiction model: a smartphone app pilot study. Child Obes (e-pub ahead of print; doi:10.1089/ chi.2014.0124).

Schroeder FA, Penta KL, Matevossian A, Jones SR, Konradi C Tapper AR et al (2008). Drug-induced activation of dopamine D (1) receptor signaling and inhibition of class I/II histone deacetylase induce chromatin remodeling in reward circuitry and modulate cocaine-related behaviors. Neuropsychopharmacology 33: 2981-2992.

Senior SL, Ninkina N, Deacon R, Bannerman D, Buchman VL, Cragg SJ et al (2008). Increased striatal dopamine release and hyperdopaminergic-like behaviour in mice lacking both alphasynuclein and gamma-synuclein. Eur J Neurosci 27: 947-957.

Shin E, Kashiwagi Y, Kuriu T, Iwasaki H, Tanaka T, Koizumi H et al (2013). Doublecortin-like kinase enhances dendritic remodelling and negatively regulates synapse maturation. Nat Commun 4: 1440.

Steindel F, Lerner R, Haring M, Ruehle S, Marsicano G, Lutz B et al (2013). Neuron-type specific cannabinoid-mediated G protein signalling in mouse hippocampus. J Neurochem 124: 795-807.

Steketee JD (2003). Neurotransmitter systems of the medial prefrontal cortex: potential role in sensitization to psychostimulants. Brain Res Brain Res Rev 41: 203-228.

Szabo B, Siemes S, Wallmichrath I (2002). Inhibition of GABAergic neurotransmission in the ventral tegmental area by cannabinoids. Eur J Neurosci 15: 2057-2061.

Tomasi D, Volkow ND (2013). Striatocortical pathway dysfunction in addiction and obesity: differences and similarities. Crit Rev Biochem Mol Biol 48: 1-19.

Topham MK, Epand RM (2009). Mammalian diacylglycerol kinases: molecular interactions and biological functions of selected isoforms. Biochim Biophys Acta 1790: 416-424.

Volkow ND, Wang GJ, Fowler JS, Tomasi D, Baler R (2012). Food and drug reward: overlapping circuits in human obesity and addiction. Curr Top Behav Neurosci 11: 1-24.

Volkow ND, Wise RA (2005). How can drug addiction help us understand obesity? Nat Neurosci 8: 555-560.

WHO (2008). Summary Report Http://Www. Who.Int/Mediacentre/ Factsheets/Fs311/En/.

Yan Z, Hsieh-Wilson L, Feng J, Tomizawa K, Allen PB, Fienberg AA et al (1999). Protein phosphatase 1 modulation of neostriatal AMPA channels: regulation by DARPP-32 and spinophilin. Nat Neurosci 2: 13-17.

Supplementary Information accompanies the paper on the Neuropsychopharmacology website (http://www.nature.com/npp) 